\title{
Review Article \\ Formulations of Amlodipine: A Review
}

\author{
Muhammad Ali Sheraz, Syed Furqan Ahsan, Marium Fatima Khan, \\ Sofia Ahmed, and Iqbal Ahmad
}

Baqai Institute of Pharmaceutical Sciences, Baqai Medical University, 51 Deh Tor, Toll Plaza, Super Highway, Gadap Road, Karachi 74600, Pakistan

Correspondence should be addressed to Muhammad Ali Sheraz; ali_sheraz80@hotmail.com

Received 8 July 2016; Accepted 20 September 2016

Academic Editor: Francisco Javier Flores-Murrieta

Copyright (C) 2016 Muhammad Ali Sheraz et al. This is an open access article distributed under the Creative Commons Attribution License, which permits unrestricted use, distribution, and reproduction in any medium, provided the original work is properly cited.

\begin{abstract}
Amlodipine $(\mathrm{AD})$ is a calcium channel blocker that is mainly used in the treatment of hypertension and angina. However, latest findings have revealed that its efficacy is not only limited to the treatment of cardiovascular diseases as it has shown to possess antioxidant activity and plays an important role in apoptosis. Therefore, it is also employed in the treatment of cerebrovascular stroke, neurodegenerative diseases, leukemia, breast cancer, and so forth either alone or in combination with other drugs. AD is a photosensitive drug and requires protection from light. A number of workers have tried to formulate various conventional and nonconventional dosage forms of $\mathrm{AD}$. This review highlights all the formulations that have been developed to achieve maximum stability with the desired therapeutic action for the delivery of AD such as fast dissolving tablets, floating tablets, layered tablets, single-pill combinations, capsules, oral and transdermal films, suspensions, emulsions, mucoadhesive microspheres, gels, transdermal patches, and liposomal formulations.
\end{abstract}

\section{Introduction}

Amlodipine (AD) belongs to the group of calcium channel blockers. The newer calcium channel blockers such as dihydropyridines, $\mathrm{AD}$, felodipine, and nisoldipine have improved vascular selectivity and longer durations of action. They bind to target receptors in a slow and sustained pattern producing a smooth onset of action with a $24 \mathrm{~h}$ control of blood pressure. Once daily dosing of these longer acting calcium channel blockers improves patient compliance and is associated with minimum encounter of side effects. The calcium channel blockers are suitable for a wide range of hypertensive patients including the elderly, black, and those with concomitant diseases that preclude the use of other antihypertensives [1].

$\mathrm{AD}$ is commonly used in the treatment of heart diseases like angina and hypertension [2]. Efforts have been made to prepare various dosage forms of $\mathrm{AD}$ to improve its efficacy and stability. Therefore, a comprehensive review of various formulations of $\mathrm{AD}$ reported in the literature has been made which would be helpful for pharmaceutical scientists and formulators in identifying and developing the most suitable dosage form of $\mathrm{AD}$.

\section{Formulations of AD}

Formulations of $\mathrm{AD}$ may contain its different salts such as besylate, mesylate, or maleate. These salts are considered interchangeably and the strength of the dosage form is determined in terms of the parent molecule, that is, $\mathrm{AD}$ [2]. Amlodipine besylate (ADB) is the most commonly used derivative of $\mathrm{AD}$ which is used for the preparation of its various dosage forms. The salts of $\mathrm{AD}$ are known to affect the physicochemical properties of the drug as the besylate salt is known to have better water solubility than AD alone. Some newer salts of $\mathrm{AD}$ such as adipate [3], camsylate [4], and nicotinate [5] were developed and compared with $\mathrm{ADB}$ for their pharmacokinetics. It was found that all newer salts were bioequivalent and showed similar pharmacokinetic characteristics to those of $\mathrm{ADB}$. $\mathrm{ADB}$ and $\mathrm{AD}$ camsylate are known to exert similar neuroprotective effects on primary cultured cortical neuronal cells by reducing oxidative stress, enhancing survival signals, and inhibiting death signals [6]. Different types of formulations of $\mathrm{AD}$ have been reported by various workers which are presented as follows. 
2.1. Tablets. AD is commercially available in tablet dosage form in once daily doses of 5 and $10 \mathrm{mg}$. It is usually given orally in the besylate form. A $6.9 \mathrm{mg}$ of $\mathrm{ADB}$ is equivalent to $5 \mathrm{mg}$ of $\mathrm{AD}$. It is well absorbed after oral administration and has a bioavailability of around $60-65 \%$ [7]. A racemate and $S$-enantiomer of ADB (levamlodipine besylate) were prepared and compared with each other. It was found that the two compounds have different melting points, solubility, dissolution rate, crystal morphology, particle size distribution, and hygroscopicity. The melting point of $S$-enantiomer was lower as compared to the racemate form which was due to its better water solubility and intrinsic dissolution property [8]. Furthermore, it has been reported that the calcium channel blocking activity of $\mathrm{AD}$ is restricted to its $S$-enantiomer, that is, $S$-AD $[9,10]$, while the other form, that is, $R$-AD exhibits a 1000 -fold lower activity $[10,11]$. It is interesting to note that $\mathrm{AD}$ is therapeutically used as a racemic mixture and both $S$ - and $R$-forms are available in $1: 1$ ratio in conventional formulations. Therefore, a tablet formulation containing only $S$-form was compared with the conventional tablets of $\mathrm{AD}$. Both formulations were found to be bioequivalent and well tolerated and no difference was observed in terms of pharmacodynamic profiles and clinical effects. Both formulations were found to be well tolerated and no serious adverse effects were noted [10]. Similarly, a tablet formulation of S-enantiomer of ADB was prepared with compatible excipients. The formulation was optimized using full factorial design and was found within limits when compared to the commercial brands of ADB in terms of appearance, dissolution, and stability [8]. On the contrary, an in vitro study was performed to evaluate the ability of $\mathrm{AD}$ and its enantiomers ( $S$ - and $R$-) to release nitric oxide in isolated coronary microvessels and to regulate tissue oxygen consumption via nitric oxide release. It was found that $\mathrm{AD}$ and its $R$-form released nitric oxide in a concentration dependent manner and reduced oxygen consumption in canine cardiac tissues while no effect was observed by the $S$ form at any concentration in either case [11].

Since AD is a photosensitive drug, an attempt has been made to formulate tablets by liquisolid technique in order to provide photoprotection to the active drug. The tablets were prepared using propylene glycol as solvent in 1:1 ratio with $\mathrm{AD}$, avicel PH102 as carrier, amorphous silicon (nanometer size), and titanium dioxide either alone or in combination as coating agents. These tablets were exposed to different radiations such as visible, UVA, and UVB for $8 \mathrm{~h}$ to determine the photoprotective effect of the coating material. The results indicated that liquisolid technique not only provided photoprotection but also improved the dissolution rate of $\mathrm{AD}$. Therefore, this technique can be used as an alternative to conventional coating methods particularly in formulations containing photosensitive drugs [12].

2.1.1. Fast Dissolving/Orodispersible Tablets. In addition to the presently marketed $\mathrm{AD}$ tablets and capsules, the novel fast dissolving tablets (also known as orodispersible, fast melting, fast dispersing, rapid dissolve, rapid melt, and/or quick disintegrating tablet formulations) offer an option to the patients who have difficulty in swallowing (i.e., dysphagia). It is a convenient and modest method of administration without the need of water $[13,14]$ with good palatability $[15,16]$. The dispersible tablets of ADB are comparatively bioequivalent to conventional tablets [17]. The main drawback of using orally disintegrating or crushed tablets of $\mathrm{AD}$ is their bitter taste $[16,18,19]$ and, therefore, taste masking of such dosage forms is very important to increase palatability [15].

The fast dissolving oral ADB tablets were prepared by direct compression method using croscarmellose (Ac-DiSol), crospovidone (Kollidon CL), and sodium starch glycolate as superdisintegrants in varying concentrations of 2, 4, and $6 \%$. Among the three disintegrants, croscarmellose in $6 \%$ concentration was found to be the most rapid by causing disintegration of the tablets within $11 \mathrm{~s}$ [20]. On the contrary, sodium starch glycolate and croscarmellose showed comparatively better results among the three disintegrants when used in the concentrations of $5-10 \%$ [21]. In another study, fast dissolving tablets of $\mathrm{ADB}$ were prepared by incorporating crospovidone and sodium starch glycolate either alone or in combination. The tablets prepared using a combination of both superdisintegrants were found to have most rapid disintegration and highest dissolution rate as compared to formulations containing a single superdisintegrants [22]. Therefore, it has been recommended to use a combination of superdisintegrants for the formulation of fast dissolving tablets of $\mathrm{ADB}[22,23]$. The solubility and dissolution of $\mathrm{ADB}$ was reported to increase when its solid dispersion was prepared with crospovidone by solvent evaporation method and then the mouth dissolving tablets were manufactured in $1: 4$ ratio [24]. The orodispersible tablets of $\mathrm{AD}$ are known to provide equivalent systemic effect to that of the conventional $\mathrm{AD}$ tablets or capsules when administered with or without water [25].

The dissolution of ADB was also enhanced when Plantago ovata mucilage (Ispaghol) was used as a natural superdisintegrant. The fast dissolving tablets were prepared by direct compression method and the concentration of the mucilage was found to be a key factor in affecting the rate of disintegration because a decrease in time with an increase in the concentration of the superdisintegrant has been noted [26]. Similarly, fenugreek seed mucilage and Ocimum basilicum (basil) gum were also employed as natural superdisintegrants in the formulation of fast dissolving tablets of ADB. The tablets were prepared by direct compression method using either of the superdisintegrants in varying concentrations (i.e., $2-10 \mathrm{mg}$ ). It was observed that the formulations containing the highest amount of the disintegrant showed the fastest disintegration due to rapid wetting, dispersion, and waterabsorption ratio. Moreover, the tablets were also found stable for three months when stored at $25 \pm 20^{\circ} \mathrm{C} / 60 \pm 5 \% \mathrm{RH}$ and $40 \pm 20^{\circ} \mathrm{C} / 75 \pm 5 \% \mathrm{RH}[27]$.

2.1.2. Sustained Release Floating Tablets. Floating drug delivery systems or hydrodynamically balanced systems are those that have lower bulk density than the gastric fluids. Due to this property the tablet remains buoyant for prolonged period of time and thus releases the drug slowly at a desired rate. However, weight measurements and swelling properties are other two important parameters required for the buoyant 
capabilities of the tablets. Polymers play an important role in controlling the release of the drug in such systems. Sometimes an effervescent component is also added that liberates $\mathrm{CO}_{2}$ when it comes in contact with the acidic gastric fluids. The liberated gas is entrapped in the gellified hydrocolloid and produces an upward motion causing floating of the tablet [28].

Pare et al. [29] formulated various floating effervescent tablets of $\mathrm{ADB}$ and studied their different physicochemical properties including the release of drug from its dosage form. The tablets were prepared by direct compression method using different hydrophilic (hydroxypropyl methylcellulose) and hydrophobic (Carbopol 934P) polymers and effervescing agents such as sodium bicarbonate and citric acid. The formulated tablets were compared with the commercial dosage forms and it was observed that their release was twice (i.e., $24 \mathrm{~h}$ ) delayed to those of the marketed products (i.e., $12 \mathrm{~h}$ ) [29].

2.1.3. Layered Tablets. Formulation of layered tablets has gained considerable popularity due to their certain advantages over conventional monolayer tablets. These advantages may include the use of two active drugs at the same time, formulation of two chemically incompatible substances in bilayer form, increased efficacy in case of combining two drugs with synergistic effect, use of two different release profile forms (quick and delayed release) of a single active drug, and better patient compliance due to decreased dosing burden $[30,31]$.

Layered tablets of ADB and atenolol were prepared as either monolayer (mixed matrix) or bilayer using similar excipients and processing technique. The bilayered tablet formulation was found to be more stable than the monolayered type. The packaging material also affected the stability of the formulations and it was observed that the stability of the tablets was increased when packed in aluminium strips compared to PVC blisters. In either case degradation in $\mathrm{ADB}$ was prominent whereas no decline in content was noted for atenolol [32]. In another study, an attempt was made to prepare bilayered effervescent floating tablets of $\mathrm{ADB}$ and hydrochlorothiazide by direct compression using various concentrations of polymers (various grades of hydroxypropyl methylcellulose such as K4M, K15M, K100M, and polyvinylpyrrolidone PVP K30). The tablets were formulated in a way to release $\mathrm{ADB}$ immediately in gas layer and hydrochlorothiazide with a sustained action. ADB was released more than $85 \%$ within 15 min while hydrochlorothiazide was released over a period of around $8 \mathrm{~h}$ [33]. Similarly, a bilayer combination of ADB with metoprolol succinate has also been reported with immediate and sustained release of each drug. The tablets were prepared by direct compression using sodium starch glycolate and pregelatinized starch as superdisintegrants and hydroxypropyl methylcellulose (K4M and K100) for sustained action. The tablets showed a first-order release of about $98 \%$ for $\mathrm{ADB}$ at $30 \mathrm{~min}$ and around $90 \%$ for metoprolol succinate in $20 \mathrm{~h}$. The stability studies performed for blister packed tablets at $25^{\circ} \mathrm{C} / 60 \%$ $\mathrm{RH}$ and $40^{\circ} \mathrm{C} / 75 \% \mathrm{RH}$ for three months were also found satisfactory [34].
2.1.4. Single-Pill (Fixed-Dose) Combinations. Film coated immediate release tablets of the combination of valsartan and $\mathrm{AD}$ were formulated and evaluated for their in vivo release profile and stability. The core tablets of the combination were prepared by dry granulation and the film coating was performed using Opadry aqueous coating dispersion. It was found that the release of each drug from the combination tablet meets the FDA guidelines for bioequivalence studies. The stability of the formulated tablets was evaluated according to the guideline of ICH. The film coated tablets were found stable both on long term (12 months) and accelerated stability studies [35]. Similarly, a study was performed to compare the pharmacokinetic profile of a combination of AD (5 mg) and benazepril $(10 \mathrm{mg})$ in tablets and capsules. The results indicated both dosage forms containing the combination of actives to be bioequivalent and well tolerated [36].

A large number of pills for the treatment of a single or multiple diseases are a major source of noncompliance in patients. Therefore, a single-pill or fixed-dose combination therapy is often preferred to reduce the polypharmacy burden and improve patients' compliance [37, 38]. A number of workers have employed AD in combination with other drugs as a single-pill and used it clinically with reasonable success. Not much information regarding the formulations is available as the studies are more clinically oriented and the combinations have been discussed with respect to their clinical outcomes only in majority of the cases. The drugs most commonly employed in combination with $\mathrm{AD}$ (i.e., single drug + AD combination) include aliskiren [39-41], atorvastatin [4252], azilsartan [53], benazepril [54, 55], fimasartan [56], indapamide $[57,58]$, irbesartan [59], olmesartan (olmesartan medoxomil) [39, 60-67], perindopril [68-72], telmisartan [73-77], and valsartan [70, 71, 78-97].

Some workers have tried triple combinations in a single pill and used it clinically, that is, two different drugs + $\mathrm{AD}$. The drug combinations with $\mathrm{AD}$ include aliskiren and hydrochlorothiazide $[98,99]$, olmesartan and hydrochlorothiazide [67, 100-102], and valsartan and hydrochlorothiazide $[88,95,101-103]$.

2.2. Capsules. Solid dispersion of drugs may provide fast dissolution but requires some time to initiate its release. For the drugs used in emergency conditions, like antihypertensive drugs, a lag time of almost zero is desirable. In order to reduce the lag time in drug release and enhance the dissolution, semisolid matrix-filled hard gelatin capsules of ADB were prepared by Tyagi et al. [104]. The solid dispersions of $\mathrm{ADB}$ were prepared through fusion method using varying concentrations of Poloxamer 407 and Plasdone S630. The solid dispersion that showed better dissolution profile was selected for the preparation of semisolid matrix. The optimized solid dispersion of ADB was mixed with Gelucire 44/14 and polyethylene glycol (PEG) 400 to make it semisolid and further mixed with PEG 6000 to suspend the particles in the matrix. The suspended particles were then transferred into hard gelatin capsules. Making semisolid matrix resulted in a threefold decrease in the lag time of ADB release as compared to its amorphous solid dispersions indicating that this approach can be used for the rapid 
therapeutic effect of the drug. The accelerated stability studies of these capsules revealed that the preparations were stable for at least three months when stored at $40 \pm 2^{\circ} \mathrm{C}$ and $75 \pm 5 \% \mathrm{RH}$ [104].

Asymmetric membrane capsules for simultaneous delivery of ADB and atenolol were formulated by dip coating (wet phase inversion) method using cellulose acetate as polymer in $10 \%$ concentration. Each active ingredient was mixed separately with the osmotic agents, that is, potassium chloride and citric acid monohydrate. Atenolol $(50 \mathrm{mg})$ was filled manually in the body while ADB (5 mg) in the cap. Compartments in the capsules were formed by using paraffin wax plug. A layer of the polymer was applied over it to avoid any leakage from each compartment followed by outer sealing of the capsules with a solution $(10 \% \mathrm{w} / \mathrm{v}$ cellulose acetate in a mixture of acetone and alcohol). The release data showed around $55 \%$ release of $\mathrm{ADB}$ at $12 \mathrm{~h}$ from capsules containing no osmotic agent while a $100 \%$ release was noted at $6 \mathrm{~h}$ for capsules containing $35 \mathrm{mg}$ of citric acid and $20 \mathrm{mg}$ of potassium chloride. In the latter case, the caps of the capsules were modified by increasing concentration of the polymer to $15 \%$, which resulted in a sustained release of $\mathrm{ADB}(\sim 95 \%)$ for $13 \mathrm{~h}$ indicating the role of the polymer in slowing down the disintegration of the capsules cap. A zero-order release was observed in the majority of cases. All capsules were found to be stable for three months when stored either in sealed or unsealed containers at $40 \pm 2.0^{\circ} \mathrm{C} / 75 \pm 5 \% \mathrm{RH}$ [105].

2.3. Oral Films. The in vitro disintegration studies for fast disintegrating films of ADB have been conducted by Shelke et al. [106] through the solvent casting technique. Sodium alginate was used as a film polymer and sodium starch glycolate as disintegrant in nine different concentrations. The study was carried out at $\mathrm{pH} 6.2$ and it was observed that the sodium alginate film on the tablet started to disintegrate in $30 \mathrm{~s}$ and almost $75-80 \%$ of the drug was released after $6 \mathrm{~min}$ in all the formulations [106].

2.4. Suspensions. In addition to many other formulations the extemporaneous suspensions of ADB $(1 \mathrm{mg} / \mathrm{mL})$ have also been prepared from the commercially available oral tablets. One of the suspensions was made by using methylcellulose (1\%) in syrup and the other using a 1:1 mixture of commercially available extemporaneous syrup vehicles, Ora-Plus and Ora-Sweet. The suspensions were stored in plastic bottles at room $\left(25^{\circ} \mathrm{C}\right)$ and refrigerated $\left(5^{\circ} \mathrm{C}\right)$ temperatures and were analyzed for their physical and chemical stability for a period of three months. The results revealed that suspensions kept under refrigerator were more stable physically and chemically to those stored at room temperature. The assay results indicated that the suspensions stored in a refrigerator retained $>90 \%$ of the drug for 91 days compared to only 56 days for the same concentration in the samples stored at room temperature. Moreover, a slight variation in $\mathrm{pH}$ was also observed in the suspensions containing methylcellulose and kept at room temperature. On the basis of these findings, it was suggested to use these suspensions as per body weight in pediatrics as well as in elderly patients who have difficulty in swallowing [107]. No significant difference in bioavailability has been reported between suspensions prepared from crushed tablets and oral tablets of AD when studied in healthy volunteers. However, the suspension was found to be very unpalatable [108].

A similar suspension formulation has also been used successfully by Rivero et al. [109] in the treatment of a 5 year old girl who developed hypertension due to a consequence of other complications. She was initially treated with nifedipine and captopril but due to poor prognosis was shifted to $\mathrm{AD}$ and enalapril, each in an oral dose of $2.5 \mathrm{mg} /$ day that showed better therapeutic effect. The tablets for adults are available in a dose of 5 and $10 \mathrm{mg}$, therefore, the prescribed dose was administered in the form of a suspension in a similar dose of $1 \mathrm{mg} / \mathrm{mL}$ as reported by Nahata et al. [107] using a mixture of Ora-Plus and Ora-Sweet [109].

2.5. Nanoemulsions. Targeted drug delivery system is gaining popularity day by day which has encouraged researchers towards the development of nanopreparations. Various oilin-water nanoemulsions of $\mathrm{AD}$ were prepared by using different concentrations of oleic acid (oil phase), tween 20 (surfactant), Transcutol P (cosurfactant), and constructing pseudoternary phase diagrams. The transdermal effect of nanoemulsions on rat's skin was determined using Franz diffusion cell. The optimum concentration of excipients that showed highest rate of permeation in the formulation was $2 \%$ for oil, $20 \%$ for surfactant, and $10 \%$ for cosurfactant. The rate of permeation was found to be affected inversely with the excipient concentrations as the highest rate was achieved with the lowest oil and surfactants concentrations. The results showed a positive response in transdermal drug delivery and proved that the nanoemulsion is a potential vehicle for enhancing skin permeation of $\mathrm{AD}$ through transdermal preparations [110].

Similarly, oral nanoemulsions of $\mathrm{ADB}$ were prepared by spontaneous emulsification method with the purpose of obtaining increased bioavailability and targeted drug delivery to the site of action. Partition coefficient, droplet size, and in vitro release of drug were analyzed in nanoemulsions following construction of pseudoternary phase diagrams. The release of ADB from oral nanoemulsions was found to be much higher than those of the tablets available in the market. The oral administration of radiolabeled formulations ${ }^{(99 \mathrm{~m}} \mathrm{Tc}$-labeled) in mice indicated about three times higher efficacy of nanoemulsions as compared to ADB suspensions. The higher bioavailability and biodistribution of ADB from nanoemulsions were due to better uptake of the drug in all organs, thus indicating the advantage of using nanoemulsions as carriers for the delivery of $\mathrm{AD}$ [111].

Another novel approach employed to enhance the bioavailability and photostability of $\mathrm{AD}$ was the preparation of redispersible dry emulsions by spray drying technique as oil-in-water emulsions. The redispersion of the dried emulsion in distilled water formed the emulsion but with a larger particle size which was 1.4-fold higher than the original emulsion (i.e., $0.24 \pm 0.30 \mu$ versus $0.17 \pm 0.02 \mu$ ). However, no further change in the droplet size of dry emulsions was observed during six months of storage at room temperature. 
The dried emulsions showed a significant photoprotection of $\mathrm{AD}$ as only $6 \%$ of the drug was degraded in comparison to $70 \%$ in ethanolic solution and $23 \%$ as dry powder when exposed to UV irradiation for $12 \mathrm{~h}$. Similarly, the in vitro release of dried emulsions (66\%) was also found to be higher than that of the powder form (48\%) at 60 min time interval with a 2.6-2.9-fold higher bioavailability as observed in rats after oral administration. All these results indicated that the dried emulsions of $\mathrm{AD}$ could be used as an effective alternative drug delivery system [112].

2.6. Mucoadhesive Microspheres for Nasal Delivery. Local or systemic delivery of drugs through nasal route has been used conventionally for the treatment of different local diseases. In the recent past, this route has gained considerable popularity because of its reliability for the delivery of drugs that are ineffective from oral route due to metabolism in the gastrointestinal tract $[113,114]$. The recent developments and the factors affecting nasal drug delivery systems have been reviewed by Mainardes et al. [113] and Jadhav et al. [114]. Nasal delivery of $\mathrm{AD}$ as mucoadhesive microspheres is another field of interest for pharmaceutical scientists as some interesting progress has been made in this regard. AD loaded microspheres are known to provide highest photostability as compared to other dosage forms including ethanolic solutions, powder, tablets, liposomes, and cyclodextrin complexes [115].

A study has been performed in which mucoadhesive chitosan microspheres of $\mathrm{ADB}$ were prepared by simple emulsification cross-linking using glutaraldehyde as crosslinking agent. Various formulation parameters such as drugpolymer ratio $(1: 1,1: 2,1: 3,1: 4$, and $1: 5)$, stabilizing agent concentration $(0.1,0.2$, and $0.3 \% \mathrm{w} / \mathrm{v})$, and stirring rate $(600$ and $1200 \mathrm{rpm}$ ) were studied. It was observed that the in vitro mucoadhesive property and size of the microspheres increased from $28 \mu$ to $52 \mu$ with an increase in chitosan concentration which could be due to the amino groups available for binding with the sialic acid residues in mucus layer and cross-linking of the polymer. On the contrary, the release of $\mathrm{ADB}$ was slowed down with an increase in polymer concentration from about $85 \%$ to $76 \%$ after $8 \mathrm{~h}$ due to matrix formation. Increase in the stirring rate reduced the median particle size diameter of the microspheres from $\sim 99 \mu$ to $36 \mu$. The microspheres were found to be spherical with smooth surface without any aggregation and were, therefore, suggested as suitable for nasal administration [116].

Similarly, hydroxypropyl guar (HPG) microspheres containing $\mathrm{ADB}$ were formulated for nasal administration by water-in-oil emulsification solvent evaporation technique in order to investigate their suitability as nasal drug delivery system. The formulation variables which could affect the preparation of the microspheres including drug-polymer $(0.5: 3,1: 3,1.5: 3$, and $2: 3)$, polymer-drug $(1: 1,2: 1,3: 1$, and $4: 1)$, and emulsifier $(0.2,0.3,0.4$, and $0.5 \% \mathrm{w} / \mathrm{v})$ concentrations, temperature $\left(60,70,80\right.$, and $\left.90^{\circ} \mathrm{C}\right)$, and agitation speed $(1400,1600,1800$, and $2000 \mathrm{rpm})$ were also studied. It was observed that an increase in emulsifier concentration, temperature, and agitation speed resulted in a decrease of particle size from about $132 \mu$ to $19 \mu$. The microspheres were found to be spherical and free flowing and showed good mucoadhesive and swelling properties. ADB was released from microspheres with a sustained action of over $8 \mathrm{~h}$. The drug entrapment efficiency of the microspheres was found to be affected by drug and polymer concentrations. An increase in the HPG concentration resulted in higher ADB entrapment with an increase in the size of the microspheres. Similarly, an increase in the drug concentration also resulted in an increased particle size but the drug entrapment was found to decrease. The formulations were also found to be stable at room $\left(25 \pm 2^{\circ} \mathrm{C} / 60 \pm 5 \% \mathrm{RH}\right)$, refrigeration (5 \pm $\left.3^{\circ} \mathrm{C}\right)$, and accelerated $\left(40 \pm 2^{\circ} \mathrm{C} / 75 \pm 5 \% \mathrm{RH}\right)$ temperatures. No significant changes were observed at the end of 90 days indicating the suitability of ADB loaded microspheres for nasal administration [117].

\subsection{Topical Formulations}

2.7.1. Gels. Gel formulations containing dexamethasone $(0.3 \%)$ and $\mathrm{ADB}(0.5 \%)$ have been formulated using carboxymethyl cellulose sodium as gelling agent, azone (laurocapram) as penetration enhancer, and propylene glycol as solvent and humectant. The gels were studied for drug penetration within flap tissues through excised rat skin. It was observed that the compound gel containing both drugs can penetrate into skin tissue which could significantly increase the survival of ischemic skin flap [118]. The gels of ADB have also been used for the treatment of feline hypertension (i.e., in cats). Gels were prepared in a commercially available vehicle, Lipoderm, which contains a proprietary liposomal component and has a smooth creamy texture and does not separate on refrigeration [119].

ADB loaded nanostructured lipid carrier gels or nanogels for intranasal delivery have been prepared by emulsion solvent diffusion and evaporation method followed by ultrasonication. Various properties of the nanogels including zeta potential, particle size, and entrapment efficiency were investigated. The gels were also characterized for drug content, $\mathrm{pH}$, and in vitro and ex vivo drug diffusion. All these studies showed that the nanogels of ADB have good sustained action as compared to the pure drug solution and nanostructured lipid carrier dispersion and, therefore, can be used for intranasal delivery of ADB [120].

2.7.2. Transdermal Patches and Films. Drug-in-adhesive transdermal patches have been prepared using $S$-amlodipine $(S-A D)$ free base (i.e., levamlodipine) and studied for in vitro and in vivo activity in rats after optimization of the formulation parameters. The $S$-AD (4\%) loaded patches were prepared using appropriate amounts of pressure-sensitive adhesive. Penetration enhancers were added to acetic ether followed by agitation at room temperature and then applied to the surface of a fluoropolymer-treated polyester release liner (ScotchPak ${ }^{\circledR}$ 1022). The mixture was than subjected to drying, cutting, and covering with a polyester backing membrane (ScotchPak 9726) followed by storage in an aluminiumplastic membrane. The patches were applied transdermally to the rats and the plasma level of $S$-AD was measured at different time intervals. It was observed that the patches can maintain drug plasma level for up to $72 \mathrm{~h}$ without any first 
pass effect and hence can be used as an effective alternative dosage form in the treatment of hypertension [121].

In another study, an attempt was made to formulate various $\mathrm{ADB}(10 \%)$ loaded films by solvent evaporation technique using different polymers such as polycaprolactone, ethylcellulose, polylactic acid, and polyhydroxyethyl methacrylate. Polyethylene glycol 400 was used as a plasticizer in a $2 \%$ concentration in each formulation. The prepared films were evaluated for parameters such as weight variation, thickness, drug content, and in vitro permeation. All films showed good physicochemical performance. The in vitro release studies indicated sustained release of $\mathrm{ADB}$ from all films over a period of $24 \mathrm{~h}$ with the slowest rate in films prepared from polyhydroxyethyl methacrylate (i.e., 79\%) [122].

2.8. Liposomal Formulations. Liposomes are spherical vesicles with at least a single lipid bilayer that are used to deliver a drug to a specific site or target in the body and to overcome any stability or toxicity related problems of the drug. Liposomes have gained tremendous popularity due to their ability of delivering both lipophilic and hydrophilic drugs [115]. AD is a lipophilic drug and is known to have better penetration ability into liposomal vesicles than other cardiovascular agents such as mexiletine and indapamide [123].

Since $\mathrm{AD}$ is sensitive to light, it requires protection to avoid degradation. To overcome this problem, a liposomal preparation of $\mathrm{AD}$ was prepared and evaluated for its photostability. It was observed that an inclusion complex between the liposome and drug was formed that resulted in a significant reduction in the photodegradation of $\mathrm{AD}$ which was higher than some other systems like solution and powder. The degradation time of $10 \% \operatorname{drug}\left(t_{0.1}\right)$ was found to be about 220 min which was better than the ethanolic solutions $\left(t_{0.1}=\right.$ $\sim 10 \mathrm{~min})$ and powder form of $\mathrm{AD}\left(t_{0.1}=111 \mathrm{~min}\right)$ [115].

$\mathrm{AD}$ possesses antioxidant properties and plays an important role in the apoptosis [124-129]. Due to this activity, targeted delivery of $\mathrm{AD}$ in liposomal preparations, either alone or in combination with other drugs, has been employed by various workers with significant success $[124,125,129]$.

\section{Conclusion}

For an effective treatment, it is of utmost importance to deliver the drug in a suitable dosage form through an appropriate route. A dosage form must be designed in a way that not only provides stability to the formulation ingredients but also gives optimum therapeutic effect. Different formulations of $\mathrm{AD}$ have been developed and the majority of these have shown acceptable stability. However, further studies regarding their in vivo efficacy and more innovations in $\mathrm{AD}$ delivery systems would definitely help in the effective treatment of various diseases. Availability of different dosage forms of $\mathrm{AD}$ would also provide a choice to physicians and pharmacists to select the most appropriate delivery system based on the patient's condition.

\section{Competing Interests}

There is no conflict of interests regarding the publication of this paper.

\section{References}

[1] J. L. Palma-Gámiz, "High blood pressure and calcium antagonism," Cardiology, vol. 88, no. 1, pp. 39-46, 1997.

[2] British National Formulary 61, BMJ Group and RPS Publishing, London, UK, 2011.

[3] H.-Y. Lee, H.-J. Kang, B.-K. Koo et al., "Clinic blood pressure responses to two amlodipine salt formulations, adipate and besylate, in adult Korean patients with mild to moderate hypertension: a multicenter, randomized, double-blind, parallelgroup, 8-week comparison," Clinical Therapeutics, vol. 27, no. 6, pp. 728-739, 2005.

[4] J.-Y. Park, K.-A. Kim, G.-S. Lee et al., "Randomized, open-label, two-period crossover comparison of the pharmacokinetic and pharmacodynamic properties of two amlodipine formulations in healthy adult male Korean subjects," Clinical Therapeutics, vol. 26, no. 5, pp. 715-723, 2004.

[5] J.-Y. Park, K.-A. Kim, P.-W. Park et al., "Comperative pharmacokinetic and pharmacodynamic characteristics of amlodipine besylate and amlodipine nicotinate in healthy subjects," International Journal of Clinical Pharmacology and Therapeutics, vol. 44, no. 12, pp. 641-647, 2006.

[6] Y. J. Lee, H.-H. Park, S.-H. Koh, N.-Y. Choi, and K.-Y. Lee, "Amlodipine besylate and amlodipine camsylate prevent cortical neuronal cell death induced by oxidative stress," Journal of Neurochemistry, vol. 119, no. 6, pp. 1262-1270, 2011.

[7] S. C. Sweetman, Martindale: The Complete Drug Reference, Royal Pharmaceutical Society, London, UK, 36th edition, 2009.

[8] Š. Hadžidedić, A. Uzunović, S. Šehić Jazić, and S. Kocova ElArini, "The impact of chirality on the development of robust and stable tablet formulation of (S-) amlodipine besylate," Pharmaceutical Development and Technology, vol. 19, no. 8, pp. 930-941, 2014.

[9] S. Goldmann, J. Stoltefuss, and L. Born, "Determination of the absolute configuration of the active amlodipine enantiomer as (-)-S: a correction," Journal of Medicinal Chemistry, vol. 35, no. 18, pp. 3341-3344, 1992.

[10] J.-Y. Park, K.-A. Kim, P.-W. Park et al., "Pharmacokinetic and pharmacodynamic characteristics of a new S-amlodipine formulation in healthy Korean male subjects: a randomized, open-label, two-period, comparative, crossover study," Clinical Therapeutics, vol. 28, no. 11, pp. 1837-1847, 2006.

[11] X.-P. Zhang, E. L. Kit, S. Mital, S. Chahwala, and T. H. Hintze, "Paradoxical release of nitric oxide by an L-type calcium channel antagonist, the R+ enantiomer of amlodipine," Journal of Cardiovascular Pharmacology, vol. 39, no. 2, pp. 208-214, 2002.

[12] A. Khames, "Liquisolid technique: a promising alternative to conventional coating for improvement of drug photostability in solid dosage forms," Expert Opinion on Drug Delivery, vol. 10, no. 10, pp. 1335-1343, 2013.

[13] Y. Fu, S. Yang, S. H. Jeong, S. Kimura, and K. Park, "Orally fast disintegrating tablets: developments, technologies, tastemasking and clinical studies," Critical Reviews in Therapeutic Drug Carrier Systems, vol. 21, no. 6, pp. 433-475, 2004.

[14] V. Parkash, S. Maan, Deepika, S. Yadav, H. Hemlata, and V. Jogpal, "Fast disintegrating tablets: opportunity in drug delivery system," Journal of Advanced Pharmaceutical Technology and Research, vol. 2, no. 4, pp. 223-235, 2011.

[15] M. Fukui-Soubou, H. Terashima, K. Kawashima, O. Utsunomiya, and T. Terada, "Efficacy, safety, and palatability 
of $\mathrm{RACTAB}^{\circledR}$ formulation amlodipine orally disintegrating tablets," Drugs in R \& D, vol. 11, no. 4, pp. 327-336, 2011.

[16] T. Uchida, M. Yoshida, M. Hazekawa et al., "Evaluation of palatability of 10 commercial amlodipine orally disintegrating tablets by gustatory sensation testing, OD-mate as a new disintegration apparatus and the artificial taste sensor," Journal of Pharmacy and Pharmacology, vol. 65, no. 9, pp. 1312-1320, 2013.

[17] Y. Liu, J. Jia, G. Liu et al., "Pharmacokinetics and bioequivalence evaluation of two formulations of $10-\mathrm{mg}$ amlodipine besylate: an open-label, single-dose, randomized, two-way crossover study in healthy chinese male volunteers," Clinical Therapeutics, vol. 31, no. 4, pp. 777-783, 2009.

[18] A. Ferrarini, A. A. Bianchetti, E. F. Fossali et al., "What can we do to make antihypertensive medications taste better for children?" International Journal of Pharmaceutics, vol. 457, no. 1, pp. 333336, 2013.

[19] G. Milani, M. Ragazzi, G. D. Simonetti et al., "Superior palatability of crushed lercanidipine compared with amlodipine among children," British Journal of Clinical Pharmacology, vol. 69, no. 2, pp. 204-206, 2010.

[20] V. Bhardwaj, M. Bansal, and P. K. Sharma, "Formulation and evaluation of fast dissolving tablets of amlodipine besylate using different super disintegrants and camphor as sublimating agent," American-Eurasian Journal of Scientific Research, vol. 5, pp. 264-269, 2010.

[21] G. S. Krushnan, R. M. Britto, J. Perianayagam et al., "Formulation and evaluation of oro dispersible tablets of amlodipine besylate," Indian Journal of Research in Pharmacy and Biotechnology, vol. 1, pp. 472-477, 2013.

[22] B. S. Raj, I. S. R. Punitha, and S. Dube, "Formulation and characterization of fast disintegrating tablets of amlodipine using superdisintegrants," Journal of Applied Pharmaceutical Science, vol. 2, no. 8, pp. 118-123, 2012.

[23] P. S. Mohanachandran, P. R. Krishna Mohan, S. Fels, K. B. Bini, B. Beenu, and K. K. Shalina, "Formulation and evaluation of mouth dispersible tablets of amlodipine besylate," International Journal of Applied Pharmaceutics, vol. 2, no. 3, pp. 1-6, 2010.

[24] R. Dahima, A. Pachori, and S. Netam, "Formulation and evaluation of mouth dissolving tablet containing amlodipine besylate solid dispersion," International Journal of ChemTech Research, vol. 2, no. 1, pp. 706-715, 2010.

[25] V. Mascoli, U. Kuruganti, A. T. Bapuji, R. Wang, and B. Damle, "Pharmacokinetics of a novel orodispersible tablet of amlodipine in healthy subjects," Journal of Bioequivalence and Bioavailability, vol. 5, no. 2, pp. 76-79, 2013.

[26] G. Gokul Ghenge, S. D. Pande, A. Ahmad, L. Jejurkar, and T. Birari, "Development and characterisation of fast disintegrating tablet of amlodipine besylate using mucilage of plantago ovata as a natural superdisintegrant," International Journal of PharmTech Research, vol. 3, no. 2, pp. 938-945, 2011.

[27] S. Sukhavasi and V. S. Kishore, "Formulation and evaluation of fast dissolving tablets of amlodipine besylate by using Fenugreek seed mucilage and Ocimum basilicum gum," International Current Pharmaceutical Journal, vol. 1, no. 9, pp. 243-249, 2012.

[28] B. N. Singh and K. H. Kim, "Floating drug delivery systems: an approach to oral controlled drug delivery via gastric retention," Journal of Controlled Release, vol. 63, no. 3, pp. 235-259, 2000.

[29] A. Pare, S. K. Yadav, and U. K. Patil, "Formulation and evaluation of effervescent floating tablet of amlodipine besylate," Research Journal of Pharmacy and Technology, vol. 1, pp. 526$530,2008$.
[30] A. Abebe, I. Akseli, O. Sprockel, N. Kottala, and A. M. Cuitiño, "Review of bilayer tablet technology," International Journal of Pharmaceutics, vol. 461, no. 1-2, pp. 549-558, 2014.

[31] I. Akseli, A. Abebe, O. Sprockel, and A. M. Cuitiño, "Mechanistic characterization of bilayer tablet formulations," Powder Technology, vol. 236, pp. 30-36, 2013.

[32] S. Aryal and N. Škalko-Basnet, "Stability of amlodipine besylate and atenolol in multi-component tablets of mono-layer and bilayer types," Acta Pharmaceutica, vol. 58, no. 3, pp. 299-308, 2008.

[33] G. Hariharan, M. Sudhakar, and R. Vinay, "Development and optimization of bilayer hydrodyanamically balanced system of Amlodipine Besylate immediate release and Hydrochlorothiazide controlled release," Asian Journal of Pharmaceutical and Clinical Research, vol. 6, no. 3, pp. 243-246, 2013.

[34] S. Jayaprakash, S. M. Halith, K. Pillai, P. Balasubramaniyam, U. M. Firthouse, and M. Boopathi, "Formulation and evaluation of bilayer tablets of amlodipine besilate and metprolol succinate," Der Pharmacia Lettre, vol. 3, no. 4, pp. 143-154, 2011.

[35] A. N. Zaid, S. Natur, A. Qaddomi et al., "Formulation and bioequivalence of two valsartan/amlodipine immediate release tablets after a single oral administration," Pakistan Journal of Pharmaceutical Sciences, vol. 27, no. 4, pp. 755-762, 2014.

[36] K.-L. Chien, C.-L. Chao, and T.-C. Su, "Bioavailability study of fixed-dose tablet versus capsule formulation of amlodipine plus benazepril: a randomized, single-dose, two-sequence, twoperiod, open-label, crossover study in healthy volunteers," Current Therapeutic Research-Clinical and Experimental, vol. 66, no. 2, pp. 69-79, 2005.

[37] B. Farrell, V. French Merkley, and N. Ingar, "Reducing pill burden and helping with medication awareness to improve adherence," Canadian Pharmacists Journal, vol. 146, no. 5, pp. 262-269, 2013.

[38] A. Hagendorff, S. Freytag, A. Müller, and S. Klebs, "Pill burden in hypertensive patients treated with single-pill combination therapy-an observational study," Advances in Therapy, vol. 30, no. 4, pp. 406-419, 2013.

[39] C. Axthelm, C. Sieder, F. Meister, and E. Kaiser, "Efficacy and tolerability of the single-pill combination of aliskiren $300 \mathrm{mg} /$ amlodipine $10 \mathrm{mg}$ in hypertensive patients not controlled by olmesartan $40 \mathrm{mg} / \mathrm{amlodipine} 10 \mathrm{mg}$," Current Medical Research and Opinion, vol. 28, no. 1, pp. 69-78, 2012.

[40] N. Glorioso, M. Thomas, C. Troffa et al., "Antihypertensive efficacy and tolerability of aliskiren/amlodipine single- Pill combinations in patients with an inadequate response to aliskiren monotherapy," Current Vascular Pharmacology, vol. 10, no. 6, pp. 748-755, 2012.

[41] D. Pfeiffer, N. Rennie, C. C. Papst, and J. Zhang, "Efficacy and tolerability of aliskiren/amlodipine single-pill combinations in patients who did not respond fully to amlodipine monotherapy," Current Vascular Pharmacology, vol. 10, no. 6, pp. 773-780, 2012.

[42] K. Azushima, K. Uneda, K. Tamura et al., "Effects of single pill-based combination therapy of amlodipine and atorvastatin on within-visit blood pressure variability and parameters of renal and vascular function in hypertensive patients with chronic kidney disease," BioMed Research International, vol. 2014, Article ID 437087, 7 pages, 2014.

[43] S. Bashir, M. U. Sherwani, I. Shabbir, and A. Batool, "Efficacy of fix dose combination (atorvastatin and amlodipine) in treatment of uncontrolled hypertension and dyslipidemia," Journal of Ayub Medical College Abbottabad, vol. 23, no. 3, pp. 97-100, 2011. 
[44] A. Delgado-Montero and J. L. Zamorano, "Atorvastatin calcium plus amlodipine for the treatment of hypertension," Expert Opinion on Pharmacotherapy, vol. 13, no. 18, pp. 2673-2685, 2012.

[45] J. Fedacko, D. Pella, P. Jarcuska et al., "Slovak trial on cardiovascular risk reduction following national guidelines with CaDUET (the STRONG DUET study)," Advances in Therapy, vol. 30, no. 1, pp. 60-70, 2013.

[46] M. A. Hussein, R. H. Chapman, J. S. Benner et al., "Does a single-pill antihypertensivelipid-lowering regimen improve adherence in us managed care enrolees? A non-randomized, observational, retrospective study," American Journal of Cardiovascular Drugs, vol. 10, no. 3, pp. 193-202, 2010.

[47] J. Hradec, J. Zamorano, and S. Sutradhar, "Post hoc analysis of the cluster randomized usual care versus caduet investigation assessing long-term risk (CRUCIAL) trial," Current Medical Research and Opinion, vol. 29, no. 6, pp. 589-596, 2013.

[48] J.-H. Kim, J. Zamorano, S. Erdine et al., "Reduction in cardiovascular risk using proactive multifactorial intervention versus usual care in younger ( $<65$ years) and older ( $\geq 65$ years) patients in the CRUCIAL trial," Current Medical Research and Opinion, vol. 29, no. 5, pp. 453-463, 2013.

[49] J. M. Neutel, W. H. Bestermann, E. M. Dyess et al., "The use of a single-pill calcium channel blocker/statin combination in the management of hypertension and dyslipidemia: a randomized, placebo-controlled, multicenter study," Journal of Clinical Hypertension, vol. 11, no. 1, pp. 22-30, 2009.

[50] J. Park, Y. Lee, S. Ko, and B. Cha, "Cost-effectiveness analysis of low density lipoprotein cholesterol-lowering therapy in hypertensive patients with type 2 diabetes in Korea: single-pill regimen (amlodipine/atorvastatin) versus double-pill regimen (amlodipine+atorvastatin)," Epidemiology and Health, vol. 37, Article ID e2015010, 2015.

[51] L. A. Simons, M. Ortiz, and G. Calcino, "Persistence with a single pill versus two pills of amlodipine and atorvastatin: the Australian experience, 2006-2010," Medical Journal of Australia, vol. 195, no. 3, pp. 134-137, 2011.

[52] M. Tanaka, R. Nishimura, T. Nishimura et al., "Effect of single tablet of fixed-dose amlodipine and atorvastatin on blood pressure/lipid control, oxidative stress, and medication adherence in type 2 diabetic patients," Diabetology and Metabolic Syndrome, vol. 6, no. 1, article 56, 2014.

[53] H. Rakugi, E. Nakata, E. Sasaki, and T. Kagawa, "Evaluation of the efficacy and tolerability of fixed-dose combination therapy of azilsartan and amlodipine besylate in Japanese patients with grade I to II essential hypertension," Clinical Therapeutics, vol. 36, no. 5, pp. 711-721, 2014.

[54] N. Reichek, R. B. Devereux, R. A. Rocha et al., "Magnetic resonance imaging left ventricular mass reduction with fixeddose angiotensin-converting enzyme inhibitor-based regimens in patients with high-risk hypertension," Hypertension, vol. 54, no. 4, pp. 731-737, 2009.

[55] P. H. Skoglund, P. Svensson, J. Asp et al., "Amlodipine + benazepril is superior to hydrochlorothiazide + benazepril irrespective of baseline pulse pressure: subanalysis of the ACCOMPLISH Trial," Journal of Clinical Hypertension, vol. 17, no. 2, pp. 141-146, 2015.

[56] H.-Y. Lee, Y.-J. Kim, T. Ahn et al., "A randomized, multicenter, double-blind, placebo-controlled, $3 \times 3$ factorial design, phase II study to evaluate the efficacy and safety of the combination of fimasartan/amlodipine in patients with essential hypertension," Clinical Therapeutics, vol. 37, no. 11, pp. 2581-2596, 2015.
[57] U. Jadhav, J. Hiremath, D. J. Namjoshi et al., "Blood pressure control with a single-pill combination of indapamide sustainedrelease and amlodipine in patients with hypertension: the EFFICIENT study," PLoS ONE, vol. 9, no. 4, Article ID e92955, 2014.

[58] P. Kawalec, P. Holko, E. Stawowczyk, Ł. Borowiec, and K. J. Filipiak, "Economic evaluation of single-pill combination of indapamide and amlodipine in the treatment of arterial hypertension in the Polish setting," Kardiologia Polska, vol. 73, no. 9, pp. 768-780, 2015.

[59] K. P. Garnock-Jones, "Irbesartan/Amlodipine: a review of its use in adult patients with essential hypertension not adequately controlled with monotherapy," American Journal of Cardiovascular Drugs, vol. 13, no. 2, pp. 141-150, 2013.

[60] L. D. Esposti, S. Saragoni, S. Buda, and E. D. Esposti, "Drug adherence to olmesartan/amlodipine fixed combination in an Italian clinical practice setting," ClinicoEconomics and Outcomes Research, vol. 6, no. 1, pp. 209-216, 2014.

[61] G. Derosa, A. F. G. Cicero, A. Carbone et al., "Evaluation of safety and efficacy of a fixed olmesartan/amlodipine combination therapy compared to single monotherapies," Expert Opinion on Drug Safety, vol. 12, no. 5, pp. 621-629, 2013.

[62] G. Derosa, A. F. G. Cicero, A. Carbone et al., "RETRACTED: variation of some inflammatory markers in hypertensive patients after 1 year of olmesartan/amlodipine single-pill combination compared with olmesartan or amlodipine monotherapies," Journal of American Society of Hypertension, vol. 7, no. 1, pp. 32-39, 2013.

[63] G. Derosa, A. F. G. Cicero, A. Carbone et al., "Effects of an olmesartan/amlodipine fixed dose on blood pressure control, some adipocytokines and interleukins levels compared with olmesartan or amlodipine monotherapies," Journal of Clinical Pharmacy and Therapeutics, vol. 38, no. 1, pp. 48-55, 2013.

[64] G. Derosa, A. F. G. Cicero, A. Carbone et al., "Olmesartan/amlodipine combination versus olmesartan or amlodipine monotherapies on blood pressure and insulin resistance in a sample of hypertensive patients," Clinical and Experimental Hypertension, vol. 35, no. 5, pp. 301-307, 2013.

[65] G. Derosa, A. F. G. Cicero, A. Carbone et al., "Results from a 12 months, randomized, clinical trial comparing an olmesartan/amlodipine single pill combination to olmesartan and amlodipine monotherapies on blood pressure and inflammation," European Journal of Pharmaceutical Sciences, vol. 51, no. 1, pp. 26-33, 2014.

[66] G. Derosa, A. F. G. Cicero, A. Carbone et al., "Different aspects of sartan + calcium antagonist association compared to the single therapy on inflammation and metabolic parameters in hypertensive patients," Inflammation, vol. 37, no. 1, pp. 154-162, 2014.

[67] M. R. Weir, W. A. Hsueh, S. D. Nesbitt et al., "A titrate-to-goal study of switching patients uncontrolled on antihypertensive monotherapy to fixed-dose combinations of amlodipine and olmesartan medoxomil \pm hydrochlorothiazide," Journal of Clinical Hypertension, vol. 13, no. 6, pp. 404-412, 2011.

[68] E. Angeloni, A. Vitaterna, P. Lombardo, M. Pirelli, and S. Refice, "Single-pill combination therapy in the initial treatment of marked hypertension: a propensity-matched analysis," Clinical and Experimental Hypertension, vol. 37, no. 5, pp. 404-410, 2015.

[69] W. J. Elliott, "Rationale for a single-pill combination of perindopril arginine and amlodipine besylate," Journal of the American Society of Hypertension, vol. 9, no. 4, pp. 257-265, 2015. 
[70] P. Kizilirmak and Z. Ongen, "Comparison of single-pill strategies first line in hypertension: perindopril/amlodipine versus valsartan/amlodipine," Journal of Hypertension, vol. 33, no. 5, pp. 1114-1116, 2015.

[71] G. Mancia, R. Asmar, C. Amodeo et al., "Comparison of singlepill strategies first line in hypertension: perindopril/amlodipine versus valsartan/amlodipine," Journal of Hypertension, vol. 33, no. 2, pp. 401-411, 2015.

[72] A. J. Scheen and J. M. Krzesinski, "Fixed combination perindopril-amlodipine (Coveram) in the treatment of hypertension and coronary heart disease," Revue Médicale de Liège, vol. 64, no. 4, pp. 223-227, 2009.

[73] S. S. Billecke and P. A. Marcovitz, "Long-term safety and efficacy of telmisartan/amlodipine single pill combination in the treatment of hypertension," Vascular Health and Risk Management, vol. 9, no. 1, pp. 95-104, 2013.

[74] J. M. Neutel, G. Mancia, H. R. Black et al., "Single-pill combination of telmisartan/amlodipine in patients with severe hypertension: results from the TEAMSTA severe HTN study," The Journal of Clinical Hypertension, vol. 14, no. 4, pp. 206-215, 2012.

[75] A. M. Sharma, G. Bakris, J. M. Neutel et al., "Single-pill combination of telmisartan/Amlodipine versus amlodipine monotherapy in diabetic hypertensive patients: an 8-week randomized, parallel-group, double-blind trial," Clinical Therapeutics, vol. 34, no. 3, pp. 537-551, 2012.

[76] D. Zhu, P. Gao, W. Holtbruegge, and C. Huang, "A randomized, double-blind study to evaluate the efficacy and safety of a singlepill combination of telmisartan $80 \mathrm{mg}$ /amlodipine $5 \mathrm{mg}$ versus amlodipine $5 \mathrm{mg}$ in hypertensive Asian patients," Journal of International Medical Research, vol. 42, no. 1, pp. 52-66, 2014.

[77] D. Zhu, P. Gao, N. Yagi, and H. Schumacher, "Efficacy and tolerability of telmisartan plus amlodipine in Asian patients not adequately controlled on either monotherapy or on low-dose combination therapy," International Journal of Hypertension, vol. 2014, Article ID 475480, 11 pages, 2014.

[78] O. Baser, L. M. Andrews, L. Wang, and L. Xie, "Comparison of real-world adherence, healthcare resource utilization and costs for newly initiated valsartan/amlodipine singlepill combination versus angiotensin receptor blocker/calcium channel blocker free-combination therapy," Journal of Medical Economics, vol. 14, no. 5, pp. 576-583, 2011.

[79] N. Braun, H.-J. Ulmer, A. Ansari, R. Handrock, and S. Klebs, "Efficacy and safety of the single pill combination of amlodipine $10 \mathrm{mg}$ plus valsartan $160 \mathrm{mg}$ in hypertensive patients not controlled by amlodipine $10 \mathrm{mg}$ plus olmesartan $20 \mathrm{mg}$ in free combination," Current Medical Research and Opinion, vol. 25, no. 2, pp. 421-430, 2009.

[80] R. Düsing, "Amlodipine/valsartan single pill combination therapy in Chinese patients not controlled on previous monotherapy," Journal of Thoracic Disease, vol. 7, no. 4, pp. 562-563, 2015.

[81] S. Eckert, S. B. Freytag, A. Müller, and S. H. G. Klebs, "Metaanalysis of three observational studies of amlodipine/valsartan in hypertensive patients with additional risk factors," Blood Pressure, vol. 22, no. 1, pp. 11-21, 2013.

[82] B. Ge, W. Peng, Y. Zhang, Y. Wen, C. Liu, and X. Guo, "Effectiveness of valsartan/amlodipine single-pill combination in hypertensive patients with excess body weight: subanalysis of China status II," Journal of Cardiovascular Pharmacology, vol. 66, no. 5, pp. 497-503, 2015.

[83] J. Huang, N.-L. Sun, Y.-M. Hao et al., "Efficacy and tolerability of a single-pill combination of amlodipine/valsartan in Asian hypertensive patients not adequately controlled with valsartan monotherapy," Clinical and Experimental Hypertension, vol. 33, no. 3, pp. 179-186, 2011.

[84] D. Hu, L. Liu, and W. Li, "Efficacy and safety of valsartan/amlodipine single-pill combination in 11,422 Chinese patients with hypertension: an observational study, Advances in Therapy, vol. 31, no. 7, pp. 762-775, 2014.

[85] Y. Karpov, N. Dongre, A. Vigdorchik, and K. Sastravaha, "Amlodipine/valsartan single-pill combination: a prospective, observational evaluation of the real-life safety and effectiveness in the routine treatment of hypertension," Advances in Therapy, vol. 29, no. 2, pp. 134-147, 2012.

[86] Y.-N. Ke, J. Huang, and J.-R. Zhu, "Efficacy and safety of the single pill combination of valsartan $80 \mathrm{mg}$ plus amlodipine $5 \mathrm{mg}$ in mild to moderate essential hypertensive patients without adequate blood pressure control by monotherapy," Zhonghua Xin Xue Guan Bing Za Zhi, vol. 37, no. 9, pp. 794-799, 2009.

[87] Y. Ke, D. Zhu, H. Hong et al., "Efficacy and safety of a singlepill combination of amlodipine/valsartan in Asian hypertensive patients inadequately controlled with amlodipine monotherapy," Current Medical Research and Opinion, vol. 26, no. 7, pp. 1705-1713, 2010.

[88] W. Khan, N. Moin, S. Iktidar et al., "Real-life effectiveness, safety, and tolerability of amlodipine/valsartan or amlodipine/valsartan/hydrochlorothiazide single-pill combination in patients with hypertension from Pakistan," Therapeutic Advances in Cardiovascular Disease, vol. 8, no. 2, pp. 45-55, 2014.

[89] P. Kizilirmak, M. Berktas, M. R. Yalcin et al., "Efficacy and safety of valsartan and amlodipine single-pill combination in hypertensive patients (PEAK study)," Türk Kardiyoloji Derneği Arşivi: Türk Kardiyoloji Derneğinin Yayın Organıdır, vol. 41, pp. 406-417, 2013.

[90] P. Kizılırmak, I. Ar, and B. Ilerigelen, "Efficacy and safety of valsartan/amlodipine single-pill combination in patients with essential hypertension (PEAK LOW)," Türk Kardiyoloji Derneği arşivi: Türk Kardiyoloji Derneğinin yayın organıdır, vol. 42, no. 4, pp. 339-348, 2014.

[91] R. Lins, A. Aerts, N. Coen et al., "Effectiveness of amlodipinevalsartan single-pill combinations: hierarchical modeling of blood pressure and total cardiovascular disease risk outcomes (The Excellent Study)," Annals of Pharmacotherapy, vol. 45, no. 6, pp. 727-739, 2011.

[92] M. A. Malesker and D. E. Hilleman, "Comparison of amlodipine/valsartan fixed-dose combination therapy and conventional therapy," Managed Care, vol. 19, pp. 36-42, 2010.

[93] K. Motozato, S.-I. Miura, Y. Shiga et al., "Efficacy and safety of two single-pill fixed-dose combinations of angiotensin II receptor blockers/calcium channel blockers in hypertensive patients (EXAMINER study)," Clinical and Experimental Hypertension, vol. 38, no. 1, pp. 45-50, 2016.

[94] A. N. Odili, B. Ezeala-Adikaibe, M. B. Ndiaye et al., "Progress report on the first sub-Saharan Africa trial of newer versus older antihypertensive drugs in native black patients," Trials, 2012, article 59.

[95] J. Sison, S. H. Assaad-Khalil, R. Najem et al., "Real-world clinical experience of amlodipine/valsartan and amlodipine/ valsartan/hydrochlorothiazide in hypertension: the EXCITE study," Current Medical Research and Opinion, vol. 30, no. 10, pp. 1937-1945, 2014.

[96] J.-G. Wang, W.-F. Zeng, Y.-S. He et al., "Valsartan/amlodipine compared to nifedipine GITS in patients with hypertension 
inadequately controlled by monotherapy," Advances in Therapy, vol. 30, no. 8, pp. 771-783, 2013.

[97] D. Zhu, K. Yang, N. Sun et al., "Amlodipine/valsartan 5/160 mg versus valsartan $160 \mathrm{mg}$ in Chinese hypertensives," International Journal of Cardiology, vol. 167, no. 5, pp. 2024-2030, 2013.

[98] Y. Huan and R. Townsend, "The single pill triple combination of aliskiren, amlodipine, and hydrochlorothiazide in the treatment of hypertension," Expert Opinion on Pharmacotherapy, vol. 13, no. 16, pp. 2409-2415, 2012.

[99] M. B. Hovater and E. A. Jaimes, "Optimizing combination therapy in the management of hypertension: the role of the aliskiren, amlodipine, and hydrochlorothiazide fixed combination," Integrated Blood Pressure Control, vol. 6, pp. 59-67, 2013.

[100] P. A. Sarafidis, "Patient Cases: 1. A patient with apparent compliance," High Blood Pressure and Cardiovascular Prevention, vol. 22, pp. 15-18, 2015.

[101] P. Stafylas, A. Mavrodi, G. Kourlaba, and N. Maniadakis, "8C.06: cost-effectiveness of two single-pill triple antihypertensive therapies based on the ambulatory blood pressure measurements," Journal of Hypertension, vol. 33, article ell1, 2015.

[102] L. Xie, F. Frech-Tamas, E. Marrett, and O. Baser, "A medication adherence and persistence comparison of hypertensive patients treated with single-, double- and triple-pill combination therapy," Current Medical Research and Opinion, vol. 30, no. 12, pp. 2415-2422, 2014.

[103] P. Stafylas, G. Kourlaba, M. Hatzikou, D. Georgiopoulos, P. Sarafidis, and N. Maniadakis, "Economic evaluation of a singlepill triple antihypertensive therapy with valsartan, amlodipine, and hydrochlorothiazide against its dual components," Cost Effectiveness and Resource Allocation, vol. 13, no. 1, article 10, 2015.

[104] V. K. Tyagi, D. Singh, and K. Pathak, "Semisolid matrixfilled hard gelatin capsules for rapid dissolution of amlodipine besilate: development and assessment," Journal of Advanced Pharmaceutical Technology and Research, vol. 4, no. 1, pp. 4249, 2013.

[105] S. Garg, K. Pathak, A. Philip, and D. Puri, "Osmotically regulated two-compartment asymmetric membrane capsules for simultaneous controlled release of anti-hypertensive drugs," Scientia Pharmaceutica, vol. 80, no. 1, pp. 229-250, 2012.

[106] P. V. Shelke, A. S. Dumbare, M. V. Gadhave et al., "Formulation and evaluation of rapidly disintegrating film of amlodipine besylate," Journal of Drug Delivery and Therapeutics, vol. 2, pp. 72-75, 2012.

[107] M. C. Nahata, R. S. Morosco, and T. F. Hipple, "Stability of amlodipine besylate in two liquid dosage forms," Journal of the American Pharmaceutical Association, vol. 39, no. 3, pp. 375-377, 1999.

[108] D. A. Lyszkiewicz, Z. Levichek, E. Kozer et al., "Bioavailability of a pediatric amlodipine suspension," Pediatric Nephrology, vol. 18, no. 7, pp. 675-678, 2003.

[109] N. L. Rivero, I. A. Santos, and A. P. Carreiro, "Amlodipine in pediatric patient with uncontrolled multifactorial hypertension. Formulation of amlodipine oral suspension," European Review for Medical and Pharmacological Sciences, vol. 16, no. 8, pp. 11171119, 2012.

[110] D. Kumar, M. Aqil, M. Rizwan, Y. Sultana, and M. Ali, "Investigation of a nanoemulsion as vehicle for transdermal delivery of amlodipine," Pharmazie, vol. 64, no. 2, pp. 80-85, 2009.
[111] G. Chhabra, K. Chuttani, A. K. Mishra, and K. Pathak, "Design and development of nanoemulsion drug delivery system of amlodipine besilate for improvement of oral bioavailability," Drug Development and Industrial Pharmacy, vol. 37, no. 8, pp. 907-916, 2011.

[112] D.-J. Jang, E. J. Jeong, H.-M. Lee, B.-C. Kim, S.-J. Lim, and C.K. Kim, "Improvement of bioavailability and photostability of amlodipine using redispersible dry emulsion," European Journal of Pharmaceutical Sciences, vol. 28, no. 5, pp. 405-411, 2006.

[113] R. M. Mainardes, M. C. Urban, P. O. Cinto, M. V. Chaud, R. C. Evangelista, and M. P. D. Gremião, "Liposomes and micro/nanoparticles as colloidal carriers for nasal drug delivery," Current Drug Delivery, vol. 3, no. 3, pp. 275-285, 2006.

[114] K. R. Jadhav, M. N. Gambhire, I. M. Shaikh, V. J. Kadam, and S. S. Pisal, "Nasal drug delivery system-factors affecting and applications," Current Drug Therapy, vol. 2, no. 1, pp. 27-38, 2007.

[115] G. Ragno, E. Cione, A. Garofalo et al., "Design and monitoring of photostability systems for amlodipine dosage forms," International Journal of Pharmaceutics, vol. 265, no. 1-2, pp. 125-132, 2003.

[116] S. Patil and R. Murthy, "Preparation and in vitro evaluation of mucoadhesive chitosan microspheres of amlodipine besylate for nasal administration," Indian Journal of Pharmaceutical Sciences, vol. 68, no. 1, pp. 64-67, 2006.

[117] N. G. N. Swamy and Z. Abbas, "Preparation and in vitro characterization of mucoadhesive hydroxypropyl guar microspheres containing amlodipine besylate for nasal administration," Indian Journal of Pharmaceutical Sciences, vol. 73, no. 6, pp. 608-614, 2011.

[118] X. Wang, X. Zhang, Y. Qin, L. Zhong, K. Liu, and J. Zhang, "Percutaneous penetration ability of dexamethasone-amlodipine besylate compound gel and its effect on survival of ischemic random skin flap," Zhongguo Xiu Fu Chong Jian Wai Ke Za Zhi, vol. 24, no. 5, pp. 566-570, 2010.

[119] W. Mixon and S. R. Helms, "Transdermal amlodipine besylate in Lipoderm for the treatment of feline hypertension: a report of two cases," International Journal of Pharmaceutical Compounding, vol. 12, no. 5, pp. 392-397, 2008.

[120] M. S. Kamble, S. M. Dange, K. K. Bhalerao et al., "Development and evaluation of amlodipine besylate nanogel," Journal of Bionanoscience, vol. 9, no. 1, pp. 22-27, 2015.

[121] Y. Sun, L. Fang, M. Zhu et al., "A drug-in-adhesive transdermal patch for S-amlodipine free base: in vitro and in vivo characterization," International Journal of Pharmaceutics, vol. 382, no. 1-2, pp. 165-171, 2009.

[122] H. V. Patel, S. S. Patel, M. M. Raj et al., "Development and characterization of matrix-membrane controlled transdermal drug delivery system of amlodipine besylate," Indo American Journal of Pharmaceutical Research, vol. 4, pp. 5306-5314, 2014.

[123] M. G. Quaglia, F. Barbato, S. Fanali et al., "Direct determination by capillary electrophoresis of cardiovascular drugs, previously included in liposomes," Journal of Pharmaceutical and Biomedical Analysis, vol. 37, no. 1, pp. 73-79, 2005.

[124] X. Li, G.-R. Ruan, W.-L. Lu et al., "A novel stealth liposomal topotecan with amlodipine: apoptotic effect is associated with deletion of intracellular $\mathrm{Ca}^{2+}$ by amlodipine thus leading to an enhanced antitumor activity in leukemia," Journal of Controlled Release, vol. 112, no. 2, pp. 186-198, 2006.

[125] X. Li, W. L. Lu, G. W. Liang et al., "Effect of stealthy liposomal topotecan plus amlodipine on the multidrug-resistant 
leukaemia cells in vitro and xenograft in mice," European Journal of Clinical Investigation, vol. 36, no. 6, pp. 409-418, 2006.

[126] R. P. Mason, I. T. Mak, M. W. Trumbore, and P. E. Mason, "Antioxidant properties of calcium antagonists related to membrane biophysical interactions," American Journal of Cardiology, vol. 84, no. 4, pp. 16-22, 1999.

[127] R. P. Mason, P. R. Leeds, R. F. Jacob et al., "Inhibition of excessive neuronal apoptosis by the calcium antagonist amlodipine and antioxidants in cerebellar granule cells," Journal of Neurochemistry, vol. 72, no. 4, pp. 1448-1456, 1999.

[128] R. P. Mason, M. W. Trumbore, and P. E. Mason, "Membrane biopphysical interactions of amlodipine result in antioxidant properties," Drugs, vol. 59, no. 2, pp. 9-16, 2000.

[129] Y. Zhang, R.-J. Li, X. Ying et al., "Targeting therapy with mitosomal daunorubicin plus amlodipine has the potential to circumvent intrinsic resistant breast cancer," Molecular Pharmaceutics, vol. 8, no. 1, pp. 162-175, 2011. 

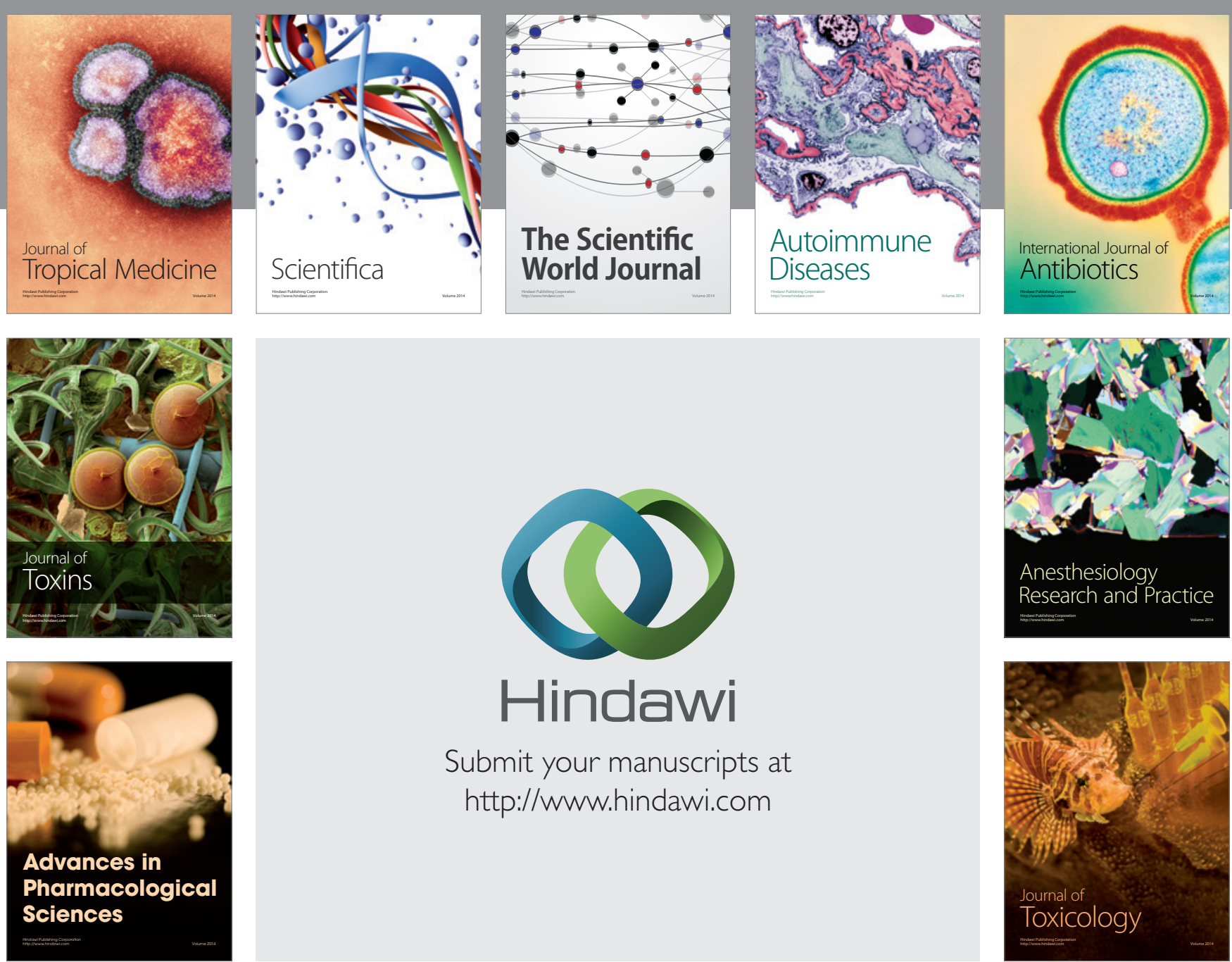

\section{Hindawi}

Submit your manuscripts at

http://www.hindawi.com
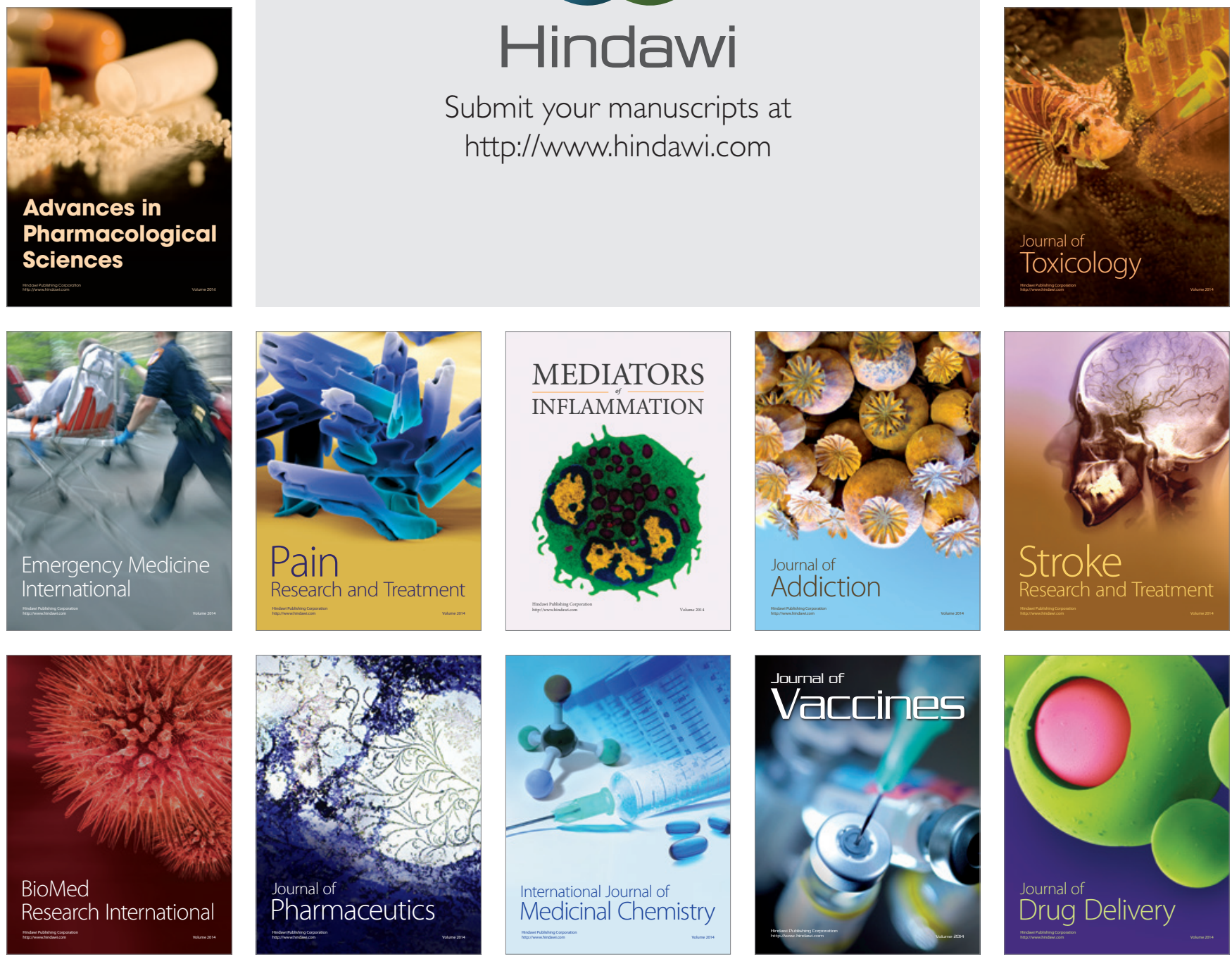